\title{
The Cause of Formation and Characteristics of Algal Blooms in Channel-Type Reservoirs
}

\author{
Chengjin Cao ${ }^{1,2,3,4 *}$,Difang Wang ${ }^{1,2}$, Bowen Yu ${ }^{1,2}$, Yang Zha ${ }^{1,2}$ and Chang Liu ${ }^{1,2}$ \\ ${ }^{1}$ School of Ecological and Environmental Sciences, Shanghai Key Lab for Urban Ecological Processes and Eco-Restoration, East China Normal University, China \\ ${ }^{2}$ Institute of Eco-Chongming, China \\ ${ }^{3}$ Key Laboratory of Geographic Information Science, Ministry of Education, East China Normal University, China \\ ${ }^{4}$ State Key Laboratory of Environmental Criteria and Risk Assessment, Chinese Research Academy of Environmental Sciences, China
}

*Corresponding author: Chengiin Cao, School of Ecological and Environmental Sciences,

East China Normal University, Shanghai 200241, China.

Received Date: September 29, 2019

Published Date: October 03, 2019

\section{Abstract}

Algal blooms (ABs) in channel-type reservoirs present an increasing problem for ecosystem functioning and human health. This paper presents long-term data of the main eutrophic factors for a tributary of channel-type reservoirs (the Three Gorges Reservoir (TGR), China). The results indicate that all surface water was neutral and alkaline, had high nitrogen and phosphorus concentrations $(0.59-27.74 \mathrm{mg} / \mathrm{L}$ and $0.005-3.444 \mathrm{mg} / \mathrm{L}$ respectively) and suitable air temperatures and water temperatures $\left(19.5-40.0^{\circ} \mathrm{C}\right.$ and $\left.8.0-31.0^{\circ} \mathrm{C}\right)$, which these factors can very easily induce $\mathrm{ABs}$ in the tributaries of channel-type reservoirs. An increasing number of ABs have been observed in the tributaries of backwater area, which have had several unique characteristics, such as the spatial "migration" of dominant algal species to other areas, the delay of the first spring HAB, and the infrequent occurrence of low-temperature ABs. In addition, with impounding of channel-type reservoirs, ABs in tributaries could more easily occur. It will be worthwhile to give greater consideration to the detrimental effects of ABs caused by sudden increases in nutrients (e.g., $\mathrm{N}$ and/or P).

Keywords: Eutrophication; Algal blooms (ABs); Channel-type reservoir; Backwater area; Three gorges reservoir (TGR)

\section{Introduction}

In this study, we performed a systematic investigation of the main eutrophication factors and unique $\mathrm{HAB}$ characteristics in the tributary of channel-type reservoir (Three Gorges Reservoir (TGR), China). The objective of this study was to reveal the main impact factors for ABs and document the trend of increasing ABs when the reservoir was functioning normally based on long-term data for the whole tributary of channel-type reservoir, and also to help develop strategies to reduce or avoid the potential risk of drinking unsafe water.

\section{Study area and sampling sites}

(Figure 1)

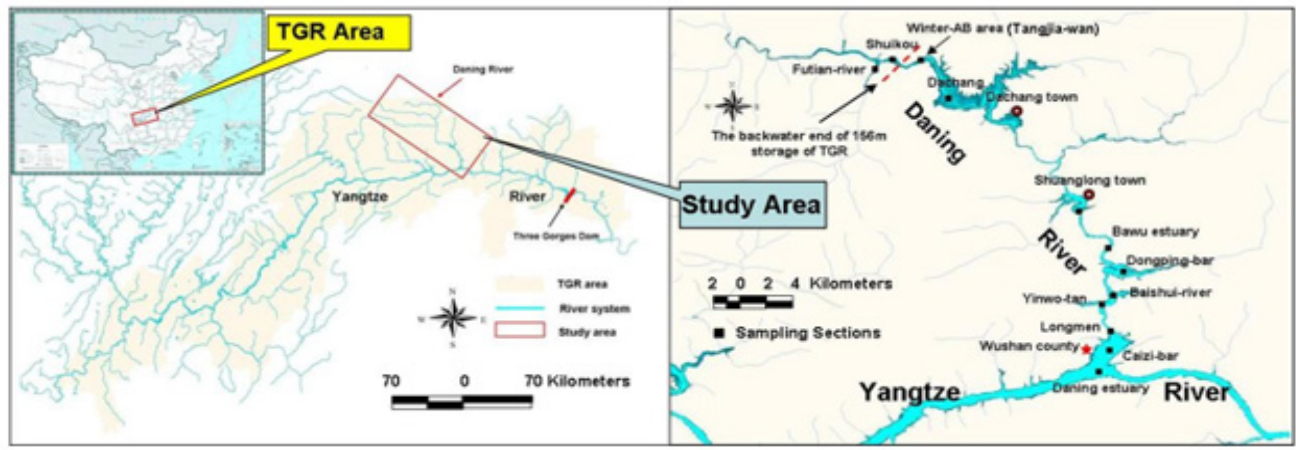

Figure 1: Map showing the study site on the tributary of the channel-type reservoirs (the Daning River, TGR, China). 


\section{Result and Discussion}

\section{Formation cause of ABs in the channel-type reservoirs}

All surface water was neutral and alkaline, had high nitrogen and phosphorus concentrations $(0.59-27.74 \mathrm{mg} / \mathrm{L}$ and $0.005-$ $3.444 \mathrm{mg} / \mathrm{L}$ respectively) and suitable air temperatures and water temperatures $\left(19.5-40.0^{\circ} \mathrm{C}\right.$ and $\left.8.0-31.0^{\circ} \mathrm{C}\right)$, which these factors can very easily induce $\mathrm{ABs}$ in the tributaries of channeltype reservoirs [1-4]. In addition, with the impounding of channeltype reservoirs, the water backward from Yangtze River greatly influenced the tributaries, without changing the input reservoir flows. Water surface significantly broadened, water depth mostly increased (add to 25-30 m), and the water was in a quasi-rest state (water velocity $<0.1 \mathrm{~m} / \mathrm{s}$ especially near the riverbank) [5]. The river twists along the gorges with steep ravines in some areas and has open, flat water in others, mainly formed by the movement of water over submerged soil. The main soil is purplish, and land use occurs mainly in the shallow soil (0.30-0.60 m deep), including paddy and dry land (especially citrus-cultivated land) [5]. Purple soil are important forms of P-rich soil. Due to the lower buffer capacity of purple soil, the risk of $\mathrm{P}$ release from it when flooded is more than that of yellow soil [6]. The mean TN and TP Were far exceeded the threshold needed for ABs (TN $0.2 \mathrm{mg} / \mathrm{L}$; TP 0.02 $\mathrm{mg} / \mathrm{L}$, [7]). In addition, TN and TP were mostly dissolved (the ratios of TDN/TN and TDP/TP were $83.85 \%$ and $60.00 \%$ respectively). TN: TP results $(>22)$ from time periods without ABs confirmed the tendency for $\mathrm{P}$ to limit total biomass.

\section{Characteristics of $\mathrm{ABs}$ in the channel-type reservoirs}

Increasing ABs were observed in the Daning River backwater area starting with the impoundment of the TGR. The ABs had longer and longer durations and higher frequencies, and the dominant species were becoming more diverse (Figure 2). With the impoundments of channel-type reservoirs, damming may have broadened the impacts on the occurrence of eutrophication and $\mathrm{ABs}$ [3]. In contrast to $\mathrm{ABs}$ in a lake, the $\mathrm{ABs}$ in the backwater area of the TGR had several of the following characteristics (Figure 2).

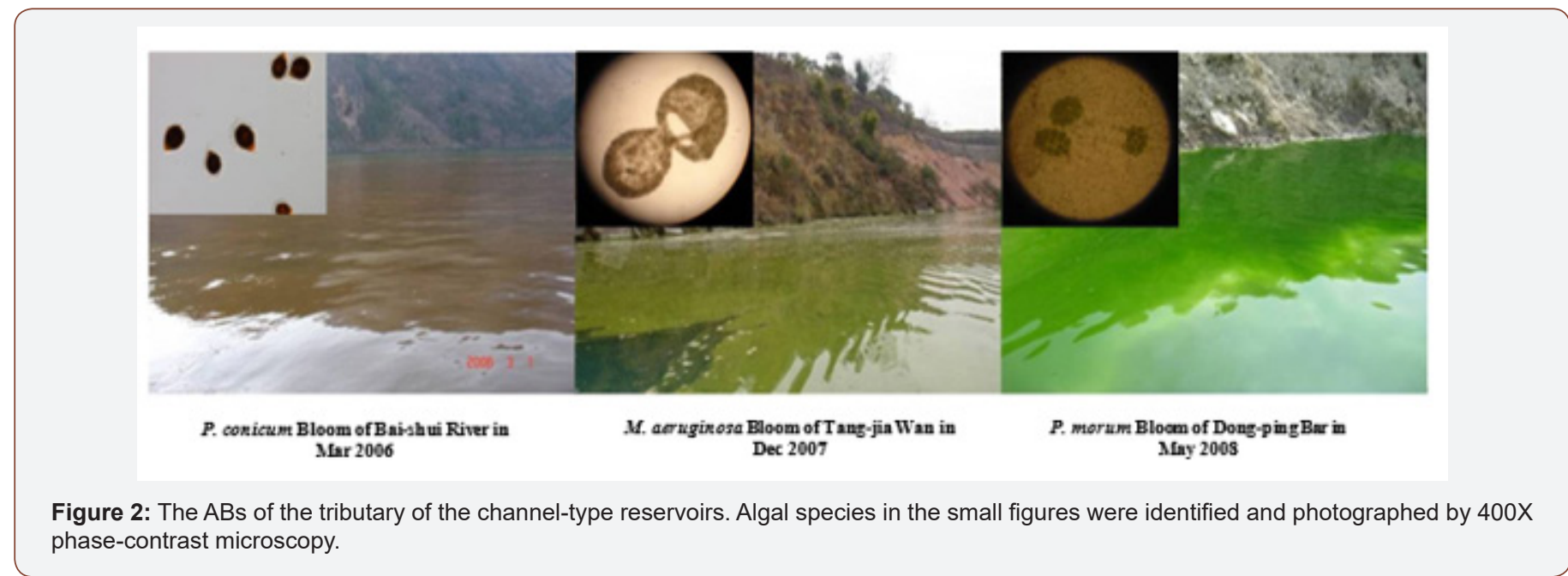

Our current dataset includes more eutrophic areas and better demonstrates that the blooms appeared in each site in chronological order from the upper to lower reaches of the tributary (Figure 3). The dominant species (eg. C. asterocostata and O. borgei Snow, and P. morum) were observed in the upstream sites first, and then they moved through the water to the downstream sites. In addition, a rare winter HAB occurred in the Tangjia-wan site from December 25, 2007 to January 23, 2008 in which the dominant species were Microcysis aeruginosa (M. aeruginosa) and Microcysis flos-aquae (M. flos-aquae), and algal cell density reached to $3.15 \times 107$ cells $/ \mathrm{L}$.
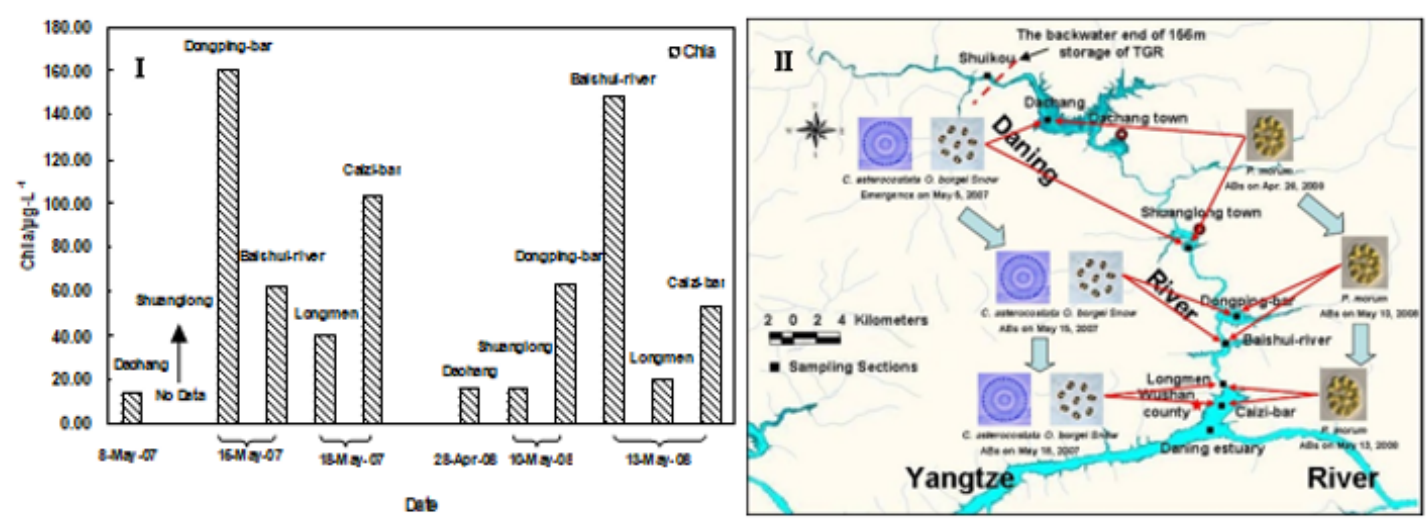

Figure 3: Migration of dominant species during ABs of the tributary of the channel-type reservoirs. 
ABs commonly occurred in the backwater area of tributaries, the typical lake type area, and had long residence times and high occurrence frequency in the midstream of the tributaries. The dominant species of algal blooms are mostly involved with O. borgei, C. microporum, Chlorococcum humicola, P. monum and C. vulgaris of Chlorophyta, P. pleuronectes and T. oblonga of Euglenophyta, M. aeruginosa and M. flos-aquae of Cyanophyta, etc. (see Figure3). Multi-algal species blooms are observed in the same time and place, and there are few algae in the estuary of tributaries to the Yangtze River. In addition, as stated above, there were typical characteristics of ABs in the channel-type reservoirs differed from other water bodies, including such factors as the spatial "moving" effect of dominant species, the delay of the first spring occurrence of ABs, and infrequent occurrence of low-temperature ABs (Figure 3).

\section{The tendency to the occurrence of ABs in the tributary of the channel-type reservoirs}

Fitting AT, WT, and light conditions, too many nutrients, and unique terrain and geological conditions, those supported, as is typical, the occurrence of ABs in the tributary. All hydrological and water quality conditions in this region, such as a broadening backwater area, reducing flow velocity, and high nutrient level, were highly conducive to the occurrence of ABs [8]. When the weather is sunny and AT and WT stay high over time, it is inevitable that widespread ABs will occur. The changing water quality and climate conditions led to the significant reduction or disappearance of ABs after the rainy season of the channel-type reservoirs. Particularly in areas under the backwater terminal, which has a flat and shallow riverbed (water depth $<4.0 \mathrm{~m}$ ), low water storage capacity, a broad backwater area, suitable light, and little flow velocity (caused by stable operation of TGR in winter), dramatic increases in some of the nutrients, such as phosphorus, could cause severe ABs even though AT and WT were low $\left(<12^{\circ} \mathrm{C}\right)[3,9]$. Hence, ABs could easily occur in the tributary of the channel-type reservoirs. It is worthwhile to pay more attention to the severe effects of ABs caused by the sudden increase of nutrients in water (e.g. $\mathrm{N}$ and/or P).

\section{Conclusion}

1. The results indicate that all surface water was neutral and alkaline, had high nitrogen and phosphorus concentrations (0.59-27.74 mg/L and 0.005-3.444 mg/L respectively) and suitable air temperatures and water temperatures (19.5 $40.0^{\circ} \mathrm{C}$ and $8.0-31.0^{\circ} \mathrm{C}$ ), which these factors can very easily induce $\mathrm{ABs}$ in the tributaries of channel-type reservoirs.

2. Results from this study suggest that $A B s$ have been increasing in the tributarie backwater area with the impoundment of channel-type reservoirs. The duration of these $\mathrm{ABs}$ is getting longer, frequency is becoming higher, and dominant species are becoming more diverse. Moreover, the $A B$ characteristics in the backwater area of channel-type reservoirs are different from other water bodies, including such factors as the spatial "moving" effect of dominant species, the delay of the first spring occurrence of ABs, and infrequent occurrence of low-temperature ABs.

3. With the impoundment of channel-type reservoirs, ABs could easily occur in its tributaries. In order to avoid the occurrence of the ABs, and reduce or avoid the potential risk of drinking unsafe water in channel-type reservoirs, $\mathrm{P}$ pollution (especially TP) controlling of spring, $\mathrm{P}$ and dissolved $\mathrm{N}$ pollution controlling of summer, TN controlling of autumn, and organic pollutants controlling of winter are respectively important. It is worthwhile to pay more attention to the negative outcomes of ABs caused by sudden increases in nutrients (e.g. N and/or P).

\section{Acknowledgement}

The work was supported by National Science and Technology Major Project of the Ministry of Science and Technology of China (2018ZX07208008), National Natural Science Foundation of China (41001347), Open Research Funding Program of KLGIS (KLGIS2016A03), Open Research Funding Program of SHUES, Open Foundation of State Key Laboratory of Environmental Criteria and Risk Assessment (CRAES), and Fundamental Research Funds for the Central Universities.

\section{Conflict of Interest}

No conflict of interest.

\section{References}

1. Gibson G, Carlson R, Simpson J, Smeltzer E, Gerritson J, et al. (2000) Nutrient criteria technical guidance manual: Lakes and reservoirs. US Environmental Protection Agency, Office of Water, USA.

2. SEPA (2002) Methods for monitoring and analysis of surface water and wastewater. Fourth edition. China Environmental Science Press, Beijing, China.

3. Cao C, Qin Y, Zheng B, Huang M (2008) Analysis of phosphorus distribution characters and their sources of the major input rivers of Three Gorges Reservoir. Environmental Science 29(2):310-315.

4. Heisler J, Glibert P, Burkholder J, Anderson D, Cochlan W, et al. (2008) Eutrophication and harmful algal blooms: A scientific consensus. Harmful Algae 8(1): 3-13.

5. China MEP (2005-2009) A monitoring report on the ecological environment of TGP, China. Ministry of Environmental Protection of P. R. China, Beijing, China.

6. Shi X, Wei S, Xie D (2004). Characteristics of Phosphorus Adsorption of The Soils in the Drawdown Area of the Three-Gorges Reservoir. Journal of Southwest Agricultural University (Natural Science) (in Chinese) 26(3): 331-335.

7. Thomann RV, Mueller JA (1987) Principles of surface water quality modeling and control. Harper \& Row, Publishers, USA.

8. Jin X, Tu Q (1990) Investigation specifications for lake eutrophication. Second edition. China Environmental Science Press, Beijing, China, pp.294-295.

9. Zheng B, Cao C, Zhang J, Huang M, Chen Z (2009) Analysis of algal blooms in Daning River of Three Gorges Reservoir (in Chinese with English abstract). Environmental Science 30:3218-3226. 